\title{
Caracterização anatômica de órgãos vegetativos do mamoeiro
}

\author{
Anatomical characterization of vegetative organs of papaya plants
}

\author{
Cláudia Elena Carneiro ${ }^{I}$ Jailson Lopes Cruz ${ }^{I}$
}

\begin{abstract}
- NOTA-
RESUMO

O mamoeiro (Carica papaya L.) é uma planta cuja importância econômica cresceu bastante nos últimos anos, bem como os trabalhos científicos relacionados ao seu crescimento e à sua fisiologia. Infelizmente, foram realizados poucos trabalhos em relação à sua anatomia. Assim, o objetivo deste trabalho é caracterizar anatomicamente plantas do

the anatomical cuts of fresh root, stem and leaf were manually performed and their visualization were made through a coloration process using safranine and astra blue. The root structure is hexarc and is characterized as non-axial. The anatomical structure of the stem is similar to petiole in the mature parts. Leaf blade showed an uniestratified epidermis with dorsiventral mesophyll and anomocytic stomata were observed in the leaf abaxial surface.
\end{abstract} mamoeiro em estádios iniciais do crescimento. Esses estudos são importantes porque podem ser utilizados, principalmente, para correlações com o crescimento e a fisiologia dessa planta. Após coletadas, amostras frescas de raiz, caule e folha foram seccionadas transversalmente à mão livre, e os cortes submetidos ao processo de coloração com safranina e azul de astra. Observou-se que a raiz apresenta estrutura hexarca e caracteriza-se como sendo não axial. A estrutura anatômica do caule, nas regiões mais maduras, assemelha-se à estrutura do pecíolo. A lâmina foliar apresenta epiderme uniestratificada com mesofilo dorsiventral, e os estômatos anomocíticos são observados na face abaxial.

Palavras-chave: Carica papaya, morfologia, raiz, folha, caule.

\section{ABSTRACT}

Papaya (Carica papaya L.) is a plant whose economic importance and scientific studies related to its growth and its physiology have greatly increased in recent years. Unfortunately, few researches in relation to its anatomy were performed. Thus, it was aimed to characterize the anatomically papaya plants in the early stages of growth. These studies are important because they can be used, mainly, for correlations with the growth and the physiology of this plant. After collected,
Key words: Carica papaya, morphology, root, leaf, stem.

Carica papaya L. é um representante da família Caricaceae, a qual possui seis gêneros e 35 espécies, ocorrendo em regiões tropicais e subtropicais das Américas e África (Van DROOGENBROECK et al., 2002; Van DROOGENBROECK et al., 2004). Existem poucos estudos anatômicos que tratam a família Caricaceae, principalmente os relacionados à espécie C. papaya, se restringindo aos estudos clássicos de SOLEREDER (1908) e METCALFE \& CHALK (1950).

O objetivo deste estudo foi caracterizar anatomicamente os órgãos vegetativos (raiz, caule e folha) de $\boldsymbol{C}$. papaya, conhecido popularmente como mamoeiro, contribuindo para a ampliação do seu conhecimento científico e biológico.

As plantas utilizadas para a realização do trabalho foram da variedade 'Sunrise solo'. Estas foram cultivadas durante 45 dias, em casa de vegetação (com

'Departamento de Ciências Biológicas, Laboratório de Micromorfologia Vegetal, Universidade Estadual de Feira de Santana (UEFS), Feira de Santana, BA, Brasil.

"Embrapa Mandioca e Fruticultura Tropical, CP 007, 44380-000, Cruz das Almas, BA, Brasil. E-mail: jailson@cnpmf.embrapa.br. Autor para correspondência. 
atenuação de $50 \%$ da luz solar incidente). Após coletadas, amostras frescas de raiz, caule e folha foram submetidas a secções transversais à mão livre. Os cortes obtidos foram clarificados com hipoclorito de sódio a $10 \%$, corados com azul de astra a 1\% e safranina a $1 \%$ na proporção de $9 \mathrm{~V}: 1 \mathrm{~V}$, respectivamente (KRAUS \& ARDUIN, 1997), e montados em gelatina glicerinada (KAISER, 1880) entre lâmina e lamínula. Para a obtenção da epiderme foliar, seguiu-se o método de Jeffrey (MACÊDO, 1997), sendo utilizando o corante safranina aquosa a $1 \%$. As amostras foram analisadas e fotomicrografadas em microscópio óptico Zeiss Axioskop 2 com câmera digital acoplada.

Os resultados evidenciaram que a raiz, em estrutura primária (Figuras 1A e 1B), apresenta epiderme uniestratificada com parede periclinal externa delgada, córtex parenquimático homogêneo desprovido de espaços intercelulares (Figura 1A), endoderme com estrias de Caspary evidentes (Figura 1B, seta), periciclo variando de uma a duas camadas (Figura 1B), cilindro vascular contendo seis pólos de xilema alternando com seis arcos de floema (Figuras 1B), caracterizando a raiz como hexarca, e medula parenquimática ocupando o centro do órgão (Figuras 1A e 1B). Em início de estrutura secundária, a raiz possui o câmbio vascular ativo entre o xilema e o floema, disposto concentricamente (Figuras 1C e 1D). Além disso, há presença de periderme com células suberificadas (Figuras 1C e 1D) e lenticelas (Figura 1D, seta), e região cortical sendo substituída pela atividade do felogênio. Foi observada a presença de tilose nos elementos de vaso do xilema (Figura 1C, detalhe). No centro do órgão, há uma medula

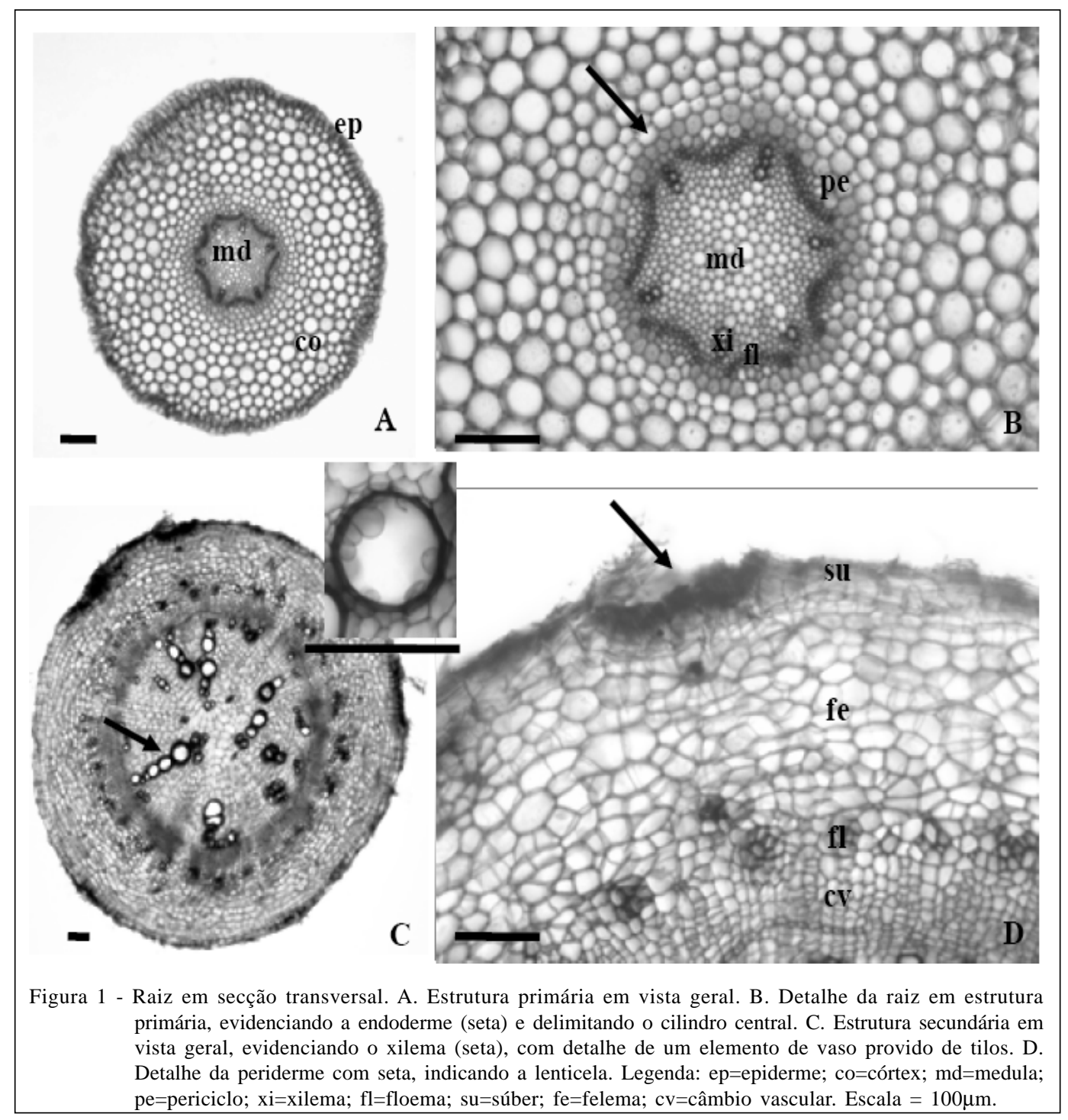

Ciência Rural, v.39, n.3, mai-jun, 2009. 
parenquimática pouco desenvolvida (Figura 1C). O xilema e o floema secundário encontram-se imaturos (Figura 1C).

O caule, em estrutura primária, apresenta epiderme uniestratificada com cutícula levemente espessa e córtex provido de colênquima na porção mais externa, sendo o restante composto por parênquima (Figura 2A). O cilindro vascular está delimitado por uma endoderme evidente (Figura 2B, seta), circundando quatro feixes vasculares separados por raios de parênquima (Figuras 2A e 2B). Também foi observada presença de medula parenquimática no centro do

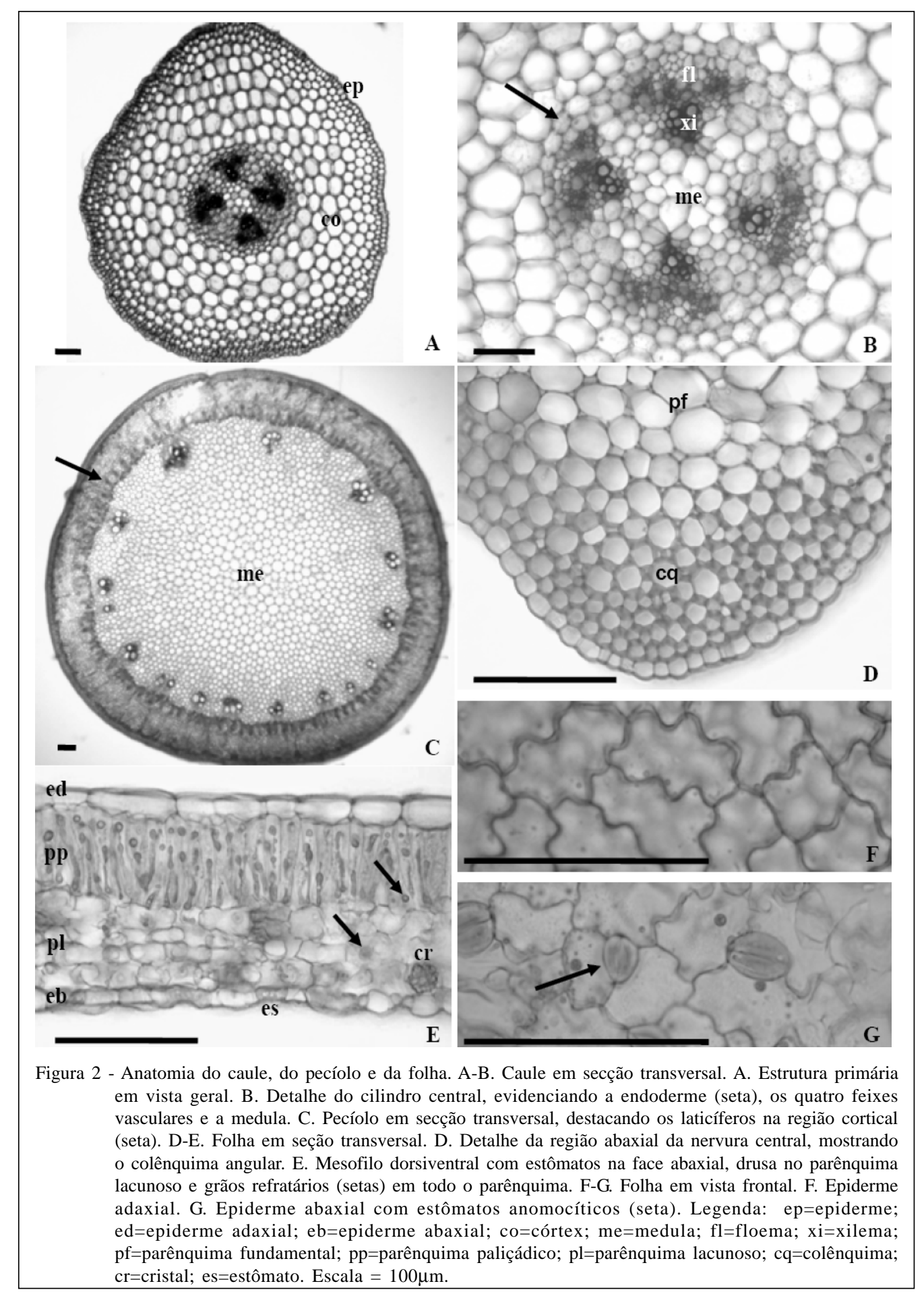

Ciência Rural, v.39, n.3, mai-jun, 2009. 
cilindro vascular (Figuras 2A e 2B). Não foi observada a presença de tricomas tectores ou glandulares na epiderme do caule.

O pecíolo possui epiderme uniestratificada com parede periclinal externa levemente espessa, córtex com uma faixa de colênquima logo abaixo da epiderme e formado por muitos laticíferos (Figura 2C, seta), os quais são articulados e se comunicam com o mesofilo da lâmina foliar. O cilindro vascular é composto por vários feixes vasculares separados por raios parenquimáticos, com o câmbio vascular entre o xilema e o floema formando um anel contínuo (Figura 2C). O centro do cilindro vascular é ocupado por uma medula parenquimática ampla (Figura 2C).

A folha apresenta mesofilo dorsiventral, com uma camada de parênquima paliçádico típico logo abaixo da epiderme adaxial e parênquima lacunoso formado, geralmente, por quatro estratos de células (Figura 2E). Cristais de oxalato de cálcio do tipo drusa foram observados no parênquima lacunoso (Figura 2E), assim como foi observada a presença de grãos fortemente refratários de tamanho grande e forma esférica em todo o parênquima (Figura 2E, setas). As células epidérmicas possuem parede e cutícula delgadas, sendo essa última desprovida de estrias (Figuras 2E). Quanto à presença de estômatos, a folha é hipoestomática (Figura 2E). Em vista frontal, as células da epiderme adaxial possuem paredes anticlinais sinuosas (Figura 2F), e as paredes da epiderme abaxial são levemente sinusosas (Figura 2G). Os estômatos são do tipo anomocíticos, ladeados por três a cinco células epidérmicas (Figura 2G). Não foram observados tricomas tectores ou glandulares na epiderme foliar. A região da nervura central da folha, em seção transversal, possui epiderme uniestratificada com paredes periclinais externas delgadas, colenquima angular logo abaixo da epiderme (Figura 2D) e sistema vascular composto de xilema em forma de ferradura, rodeado por porções de floema. Na região de transição entre a nervura central e o mesofilo, há diferenciação morfológica evidente do parênquima clorofiliano em paliçádico e lacunoso, os quais preenchem todo o restante da folha até a margem.

De acordo com as observações realizadas, conclui-se que a estrutura anatômica do tipo hexarca apresentada pelas amostras de raízes analisadas caracteriza uma raiz lateral e não uma raiz axial. Supõese que a raiz axial desenvolva rapidamente as raízes laterais para dar suporte à plântula. Os laticíferos estão presentes no caule (quando em início de desenvolvimento secundário) e nas folhas (acompanhando os feixes vasculares), ausentando-se nas raízes. Tal resultado está de acordo com SOLEREDER (1908) e METCALFE \& CHALK (1950). Não foi observada a presença de tricomas glandulares no caule e na folha, como citado por aqueles autores. A estrutura anatômica do caule, nas partes mais maduras (em início de estrutura secundária), assemelha-se à do pecíolo. Segundo METCALFE \& CHALK (1950), os grãos refratários arredondados encontrados no parênquima da folha são de natureza de um aldeído; porém, não foram feitos testes histoquímicos para verificar tal informação.

\section{REFERÊNCIAS}

KAISER, E. Verfahren zur herstellung einer tadellosen glyceringelatine. Botanisch Zentralb, Stuttgart, v.180, p.25-26, 1880.

KRAUS, J.E.; ARDUIN, M. Manual básico de métodos em morfologia vegetal. Seropédica: Universidade Rural do Rio de Janeiro, 1997. 198p.

MACÊDO, N.A. Manual de técnicas em histologia vegetal. Feira de Santana: Universidade Estadual de Feira de Santana, 1997. 96p.

METCALFE, C.R.; CHALK, L. Anatomy of the dicotyledons. Oxford: Claredon, 1950. 1500p.

SOLEREDER, H. Systematic anatomy of the dicotyledons. Oxford: Claredon, 1908. 643p.

VAN DROOGENBROECK, B. et al. AFLP analysis of genetic relationships among papaya and its wild relatives (Caricaceae) from Ecuador. Theoretical and Applied Genetics, v.105, p.289-297, 2002. Disponível em: http://www.springerlink.com/ content/dtvx4a4lqkg6eagm/. Doi: 10.1007/s00122-002-0983-4.

VAN DROOGENBROECK, B. et al. Phylogenetic analysis of the highland papayas (Vasconcellea) and allied genera (Caricaceae) using PCR-RFLP. Theoretical and Applied Genetics, v.108, p.1473-1486, 2004. Disponível em: http://www.springerlink.com/ content/ylktwc2y2r88xcrc/. Doi: 10.1007/s00122-003-1575-7. 